\title{
Impact of ticagrelor monotherapy on two-year clinical outcomes in patients with long stenting: a post hoc analysis of the GLOBAL LEADERS trial
}

Takahashi, Kuniaki ; Chichareon, Ply ; Modolo, Rodrigo ; Kogame, Norihiro ; Chang, Chun Chin ; Tomaniak, Mariusz ; Moschovitis, Aris ; Curzen, Nick ; Haude, Michael ; Jung, Werner ; Holmvang, Lene ; Garg, Scot ; Tijssen, Jan G P ; Wykrzykowska, Joanna J ; de Winter, Robbert J ; Hamm, Christian ; Steg, Philippe Gabriel ; Stoll, Hans-Peter ; Onuma, Yoshinobu ; Valgimigli, Marco ; Vranckx, Pascal ; Windecker, Stephan ; Serruys, Patrick W

\begin{abstract}
Aims: The aim of this study was to evaluate the impact of a novel antiplatelet regimen in patients with increasing total stent length (TSL). Methods and results: This is a post hoc analysis of the GLOBAL LEADERS trial, a prospective, multicentre, open-label, randomised trial, investigating the impact of the experimental strategy (one-month dual antiplatelet therapy [DAPT] followed by 23month ticagrelor monotherapy) versus the reference regimen (12-month DAPT followed by 12-month aspirin monotherapy) in patients with a Biolimus A9-eluting stent (BES). The primary endpoint was the composite of all-cause death and new Q-wave myocardial infarction (MI), and the secondary endpoint was Bleeding Academic Research Consortium (BARC) type 3 or 5 bleeding at two years. To investigate the association between total stent length and outcomes, groups were compared in quartiles according to TSL; the fourth quartile group was at significantly higher ischaemic risk at two years. In that stratum (TSL 46 $\mathrm{mm}$ ), the experimental strategy significantly reduced the risk of the primary endpoint (hazard ratio [HR] 0.67, 95\% confidence interval [CI]: 0.49-0.90; pinteraction=0.043), while demonstrating a similar risk of BARC type 3 or 5 bleeding (HR 0.99, 95\% CI: 0.66-1.49; pinteraction=0.975). Conclusions: Ticagrelor monotherapy could potentially balance ischaemic and bleeding risks, thereby achieving a net clinical benefit in patients with a TSL $46 \mathrm{~mm}$ with a BES.
\end{abstract}

DOI: https://doi.org/10.4244/eij-d-19-00498

Posted at the Zurich Open Repository and Archive, University of Zurich

ZORA URL: https://doi.org/10.5167/uzh-192131

Journal Article

Published Version

Originally published at:

Takahashi, Kuniaki; Chichareon, Ply; Modolo, Rodrigo; Kogame, Norihiro; Chang, Chun Chin; Tomaniak, Mariusz; Moschovitis, Aris; Curzen, Nick; Haude, Michael; Jung, Werner; Holmvang, Lene; Garg, Scot; Tijssen, Jan G P; Wykrzykowska, Joanna J; de Winter, Robbert J; Hamm, Christian; Steg, Philippe Gabriel; Stoll, Hans-Peter; Onuma, Yoshinobu; Valgimigli, Marco; Vranckx, Pascal; Windecker, Stephan; Serruys, Patrick W (2020). Impact of ticagrelor monotherapy on two-year clinical outcomes in patients with long stenting: a post hoc analysis of the GLOBAL LEADERS trial. EuroIntervention, 16(8):634-644.

DOI: https://doi.org/10.4244/eij-d-19-00498 


\title{
Q
}

\section{Impact of ticagrelor monotherapy on two-year clinical outcomes in patients with long stenting: a post hoc analysis of the GLOBAL LEADERS trial}

\author{
Eurolntervention 2020;16:634-644. DOI: 10.4244/EIJ-D-19-00498
}

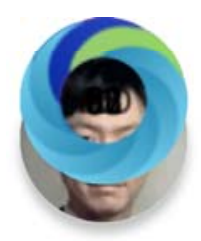

Kuniaki Takahashi ${ }^{1}$, MD; Ply Chichareon 1,2, MD; Rodrigo Modolo1,3, MD; Norihiro Kogame', MD; Chun Chin Chang ${ }^{4}$, MD; Mariusz Tomaniak ${ }^{4,5}$, MD; Aris Moschovitis ${ }^{6}$, MD; Nick Curzen7, BM (Hons), PhD; Michael Haude ${ }^{8}$, MD; Werner Jung ${ }^{9}$, MD; Lene Holmvang ${ }^{10}$, MD, DMSc; Scot Garg" ${ }^{11}$, MD, PhD; Jan G.P. Tijssen 1,12, PhD; Joanna J. Wykrzykowska', MD, PhD; Robbert J. de Winter', MD, PhD; Christian Hamm $^{13}$, MD; Philippe Gabriel Steg ${ }^{14}$, MD; Hans-Peter Stol15, MD; Yoshinobu Onuma ${ }^{16}$, MD, PhD; Marco Valgimigli17, MD, PhD; Pascal Vranckx ${ }^{18}$, MD, PhD; Stephan Windecker ${ }^{17}$, MD; Patrick W. Serruys $^{16}, M D, P h D$

1. Academic Medical Center, University of Amsterdam, Amsterdam, the Netherlands; 2. Division of Cardiology, Department of Internal Medicine, Faculty of Medicine, Prince of Songkla University, Songkhla, Thailand; 3. Department of Internal Medicine, Cardiology Division, University of Campinas (UNICAMP), Campinas, Brazil; 4. Department of Interventional Cardiology, Thoraxcenter, Erasmus Medical Center, Rotterdam, the Netherlands; 5. First Department of Cardiology, Medical University of Warsaw, Warsaw, Poland; 6. Tiefenauspital, Bern, Switzerland; 7. University Hospital Southampton, Southampton, and Faculty of Medicine, University of Southampton, Southampton, United Kingdom; 8. Städtische Kliniken Neuss, Lukaskrankenhaus GmbH, Neuss, Germany; 9. Schwarzwald-Baar Klinikum, Villingen-Schwenningen, Germany; 10. Copenhagen University HospitalRigshospitalet, Copenhagen, Denmark; 11. Royal Blackburn Hospital, Blackburn, United Kingdom; 12. Cardialysis B.V., Rotterdam, the Netherlands; 13. Kerckhoff Campus, University of Giessen, Bad Nauheim, Germany; 14. FACT (French Alliance for Cardiovascular Trials), Université Paris-Diderot, Paris, France; 15. Biosensors Clinical Research, Morges, Switzerland; 16. Department of Cardiology, National University of Ireland, Galway, Ireland; 17. Department of Cardiology, University of Bern, Inselspital, Bern, Switzerland; 18. Jessa Ziekenhuis, Faculty of Medicine and Life Sciences at the Hasselt University, Hasselt, Belgium

Aims: The aim of this study was to evaluate the impact of a novel antiplatelet regimen in patients with increasing total stent length (TSL).

Methods and results: This is a post hoc analysis of the GLOBAL LEADERS trial, a prospective, multicentre, open-label, randomised trial, investigating the impact of the experimental strategy (one-month dual antiplatelet therapy [DAPT] followed by 23-month ticagrelor monotherapy) versus the reference regimen (12-month DAPT followed by 12-month aspirin monotherapy) in patients with a Biolimus A9-eluting stent (BES). The primary endpoint was the composite of all-cause death and new Q-wave myocardial infarction (MI), and the secondary endpoint was Bleeding Academic Research Consortium (BARC) type 3 or 5 bleeding at two years. To investigate the association between total stent length and outcomes, groups were compared in quartiles according to TSL; the fourth quartile group was at significantly higher ischaemic risk at two years. In that stratum (TSL $\geq 46 \mathrm{~mm}$ ), the experimental strategy significantly reduced the risk of the primary endpoint (hazard ratio [HR] 0.67, 95\% confidence interval [CI]: 0.49-0.90;
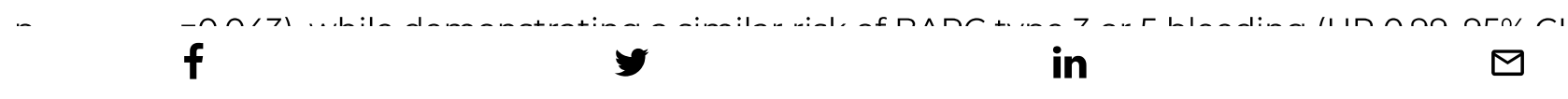
0.66-1.49; interaction $=0.975$ ).

Conclusions: Ticagrelor monotherapy could potentially balance ischaemic and bleeding risks, thereby achieving a net clinical benefit in patients with a TSL $\geq 46 \mathrm{~mm}$ with a BES.

SIGN IN TO READ AND DOWNLOAD THE FULL ARTICLE

\title{
LOGIN
}

Forgot your password?

\begin{abstract}
NO ACCOUNT YET?
SIGN UP FOR FREE!
\end{abstract}

\section{CREATE MY PCR ACCOUNT}

Join us for free and access thousands of articles from Eurolntervention, as well as presentations, videos, cases from PCRonline.com

acs/nste-acs adjunctive pharmacotherapy drug-eluting stent stable angina

\section{Read next article}

Bioresorbable vascular scaffold versus metallic drug-eluting stent in patients at high risk of restenosis: the COMPARE-ABSORB randomised clinical trial

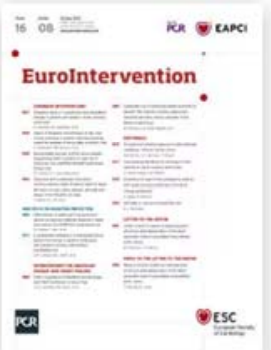

RELATED ISSUE

Volume 16 Number 8

> VIEW CONTENTS

\section{TOOLBOX}


Impact of ticagrelor monotherapy on two-year clinical outcomes in patien... https://eurointervention.pcronline.com/article/impact-of-ticagrelor-mono...

Citations

Âs'r for à iteprini

Request permissions

\section{METRICS}

\section{Dimensions Badge}

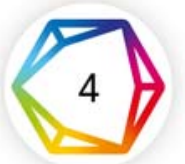
4 Total citations
4 Recent citations
n/a Field Citation Ratio
n/a Relative Citation Ratio

Altmetric
10
Mendeley (4)

Twitter (15)

\section{POPULAR THIS MONTH}

An EAPCI Expert Consensus Document on Ischaemia with Non-Obstructive Coronary Arteries in Collaboration with European Society of Cardiology Working Group on Coronary Pathophysiology \& Microcirculation Endorsed by Coronary Vasomotor Disorders International Study Group.

Vijay Kunadian et al

Impact of the COVID-19 pandemic on interventional cardiology practice: results of the EAPCI survey

Marco Roffi et al

Double-kissing culotte technique for coronary bifurcation stenting

Gabor G. Toth et al

2018 ESC/EACTS Guidelines on myocardial revascularization

Franz-Josef Neumann et al

Percutaneous recanalisation of chronic total occlusions: 2019 consensus document from the EuroCTO Club

Alfredo R. Galassi et al

\section{LATEST NEWS}




\section{Q}

NEW ISSUE

Radiation protection, ticagrelor monotherapy, the COMPARE-ABSORB trial, the BASILICA technique...

NOVEMBER 12, 2020

\section{NEW \\ Impact of Pulmonary Ridge Coverage after Left Atrial Appendage Occlusion}

NOVEMBER 18, 2020

NEW

Invasive assessment of a myocardial bridge

NOVEMBER 4, 2020

EDITORIAL

ASA-free strategy in ACS

Usman Baber

NOVEMBER 12, 2020

Popular Tavi-A, TAILOR-PCI, ATPCI, PORTICO-IDE and more (Thanks to the support of Biotronik)

NOVEMBER 12, 2020 


\section{Guidelines, consensus \& position papers}

AUGUST 28, 2020

EDITORIAL

Bioresorbable scaffold déjà vu

Dean J. Kereiakes

NOVEMBER 4, 2020

\section{CORONARY}

Percutaneous coronary intervention for bifurcation coronary lesions: the 15th consensus document from the European Bifurcation Club $\mathrm{a}$

Burzotta F et al

Supporting evidence for ST-segment elevation myocardial infarction from optical coherence tomography Satogami K et al

One-step anatomic and function testing by cardiac CT versus second-line functional testing in symptomatic patients with coronary artery stenosis: head-to-head comparison of CT-derived fractional flow reserve and myocardial perfusion imaging Westra J et al

\section{VALVULAR DISEASE}

Fatal Acute Mesenteric Ischemia Following Transcatheter Aortic Valve Replacement del Val $D$ et al

Clinical Impact of Intervention Strategies after failed Transcatheter Mitral Valve Repair Alessandrini $\mathrm{H}$ et al

Percutaneous mitral valve leaflet repair: ongoing directions and future perspectives Maisano F, Taramasso M 


\section{HEART FAILURE}

The EURO SHOCK Trial: Design, Aims and Objectives Randomised comparison of Extra Corporeal Membrane Oxygenation (ECMO) delivered after acute-PCI plus standard of care versus standard of care alone after acute $\mathrm{PCl}$, in patients presenting with Acute Coronary syndrome and Cardiogenic Shock.

Banning $A$ et al

Percutaneous mitral valve leaflet repair: ongoing directions and future perspectives

Maisano F, Taramasso M

Deep Sedation versus General Anaesthesia for Transcatheter Mitral Valve Repair: An Individual-Patient Data Meta-analysis of Observational Studies.

Jobs A et al

\section{PERIPHERAL}

Multistage Strategy With Perfusion SPECT and CT Pulmonary Angiogram in Balloon Pulmonary Angioplasty for Totally Occluded Lesions in CTEPH

Hosokawa Ket al

EAPCI Core Curriculum for Percutaneous Cardiovascular Interventions (2020): Committee for Education and Training European Association of Percutaneous Cardiovascular Interventions (EAPCI) A branch of the European Society of Cardiology

Van Belle E et al

Fistula between the right pulmonary artery and left atrium in a newborn: management and successful interventional treatment.

Michalak K et al

\section{HYPERTENSION}

EAPCI Core Curriculum for Percutaneous Cardiovascular Interventions (2020): Committee for Education and Training European Association of Percutaneous Cardiovascular Interventions (EAPCI) A branch of the European Society of Cardiology

Van Belle E et al

Early Results of the Revivent TC Procedure for Treatment of Left Ventricular Aneurysm and Heart Failure due to Ischemic Cardiomyopathy 8

Wang $Y$ et al

Pulmonary artery denervation using catheter-based ultrasonic energy $\mathbf{a}$

Rothman A et al

\section{STROKE}

Impact of Pulmonary Ridge Coverage after Left Atrial Appendage Occlusion

Freixa $X$ et al

Heterogeneity of debris captured by cerebral embolic protection filters during TAVI

Kroon $\mathrm{H}$ et al

First-in-human results of the OMEGA ${ }^{\mathrm{TM}}$ Left Atrial Appendage Occluder for Patients with Non-Valvular Atrial Fibrillation Intillin-nat n 
Impact of ticagrelor monotherapy on two-year clinical outcomes in patien... https://eurointervention.pcronline.com/article/impact-of-ticagrelor-mono...

sinout the jel! $r$ al

Editorial team

Disclaimer

Privacy policy

\section{Readers}

Current issue

Archives

Subscribe

\section{Authors}

Submit your paper

Instructions

\section{Services}

Advertise

Reprints / ePrints

Rights and permissions

\section{Textbooks}

The PCR-EAPCI textbook

The history of angioplasty

Percutaneous cardiac interventions

Coronary stenosis

\section{Follow us}

Facebook

Twitter

Impact factor: 3.993

2019 Journal Citation Reports ${ }^{\circledR}$

Science Edition (Clarivate Analytics, 2020)

Online ISSN 1969-6213 - Print ISSN 1774-024X

(c) 2005-2020 Europa Group - All rights reserved 